\title{
Lexical Alternatives as a Source of Pragmatic Presuppositions
}

\author{
Dorit Abusch \\ Cornell University
}

\section{Introduction}

This paper is about the presuppositions of verbs like know and stop. Example (1) has a factive implication that the cat is on the mat, and a belief implication that John believes that the cat is on the mat. Implication is used as neutral cover term for presuppositions, logical entailments, and conversational implicatures.

(1) John knows that the cat is on the mat.

(2) gives two possibilities for the lexical entry of know. In (2a), the two implications are written in as entailments by making them conjuncts. In (2b), I use the partial operator $\partial$ from Beaver (1995) as a presupposition operator on the factive implication. This makes the factive implication $p$ a semantic presupposition. ${ }^{1}$
a. $\mathrm{p} \wedge \mathrm{x}$ believe $\mathrm{p}$
b. $\partial p \wedge x$ believe $p$

I assume that semantic presuppositions are encoded in the semantic values of sentences, using truth value gaps or definedness of a file change potentials. ${ }^{2} \mathrm{~A}$ pragmatic presupposition of an utterance is a proposition $p$ such that in making the utterance, the speaker communicates that he takes $p$ to follow from the current common ground of shared information. Typically, if a sentence $\mathrm{S}$ has a semantic presupposition $p$, and a speaker asserts $\mathrm{S}$, then the speaker pragmatically presupposes $p$.

Stalnaker (1974) introduced the project of using the lexical representation (2a) without a semantic presupposition, and deriving the pragmatically presupposed status of the factive implication by conversational reasoning. ${ }^{3}$ I think this project is attractive for what I call soft triggers, which are presupposition triggers where the presuppositional behavior is weak and easily suspendable. Karttunen (1971) mentioned that it is easy to suspend the factive implication of discover. In typical utterances, (3a) does not pragmatically presuppose that the speaker has not told the truth. The same holds for (3b) and (3c). (The examples are from Karttunen (1971).)

(3) a. Did you discover that you had not told the truth?

b. If I discover later that I have not told the truth, I will confess it to everyone.

c. It is possible that I will discover later that I have not told the truth. 
Stalnaker pointed out that the pragmatic presupposition of discover correlates with contextual factors and indexicality. (4a) tends to presuppose that Loren is now in New York. But if we switch to the first person as in (4b), the presupposition drops out. Stalnaker takes this as evidence for a pragmatic derivation of the presupposition. And in fact, I find the presupposition even in (4a) weak or optional. (These examples are from Chierchia and McConnell-Ginet (1990).)

a. If Pavarotti discovers that Loren is now in New York, he will be angry.

b. If I discover that Loren is now in New York, I'll be angry. (Pavarotti is speaker.)

Now I will review some lexical items which, following Simons (2001), I consider soft triggers.

Aspectual verbs like stop and continue pragmatically presuppose the truth or falsity of their complements at a time immediately preceding their eventuality time. The presupposition of (5a) is that right before January 1 , John smoked. The angle sign marks the pragmatic presupposition. (5b) shows that the presupposition survives negation, and (5c) shows that it survives conditionalization. (5d) is an example where the presupposition is suspended. Suppose you receive in the mail a brochure addressed to resident which says (5d). Intuitively, there is no implication that the authors of the brochure take it as common ground that you ever smoked. This connects with the fact that the authors of the brochure have very little information about you. (Example (5d) is modified from Kadmon (2001).)
a. John stopped smoking on January 1 .
$>$ Right before January 1, John smoked.
b. John didn't stop smoking.
c. If John stops smoking, Mary will buy him a camera.
d. In a brochure addressed to resident:

If you stopped smoking in 2001 , you are eligible for a payment from the Tobacco Indemnity Fund.

I already discussed factives. (6a) and (6b) intuitively presuppose that Mary is having an affair, and in (6c) the presupposition is suspended.

(6) a. John knows that Mary is having an affair.

b. John doesn't know that Mary is having an affair.

c. John suspects Mary is having an affair. He doesn't know she is.

Another group of soft triggers are achievement verbs like win which entail a preparatory activity. (7a) seems to presuppose that Alberto participated in the race; this is supported by $(7 \mathrm{~b})$, where the presupposition survives negation. This 
presupposition goes away in (7c): we can use it immediately after Alberto has won the 2002 race, without assuming that he is going to participate in the 2003 race.

a. Alberto won the race.

b. Alberto didn't win the race.

$>$ Alberto participated in the race.

c. If Alberto wins the 2003 Falmouth Roadrace, he will have more Falmouth Roadrace victories than anyone else in history.

Notice that in this case, the context does not rule out Alberto's participating in the 2003 race, it just suggests that the speaker may be ignorant about the matter.

\section{Differences in suspendability}

In this section, I will look at the differences in suspendability between soft and hard triggers. (8) is another example of the suspension of the presupposition of stop. Intuitively, (8) does not presuppose that John used to smoke. (9) is a similar example with continue. Intuitively, it does not presuppose that John will miss the first meeting. However without the disjunction, John will continue missing meetings presupposes that he missed meetings before.

(8) John either stopped smoking, or started smoking.

(9) After the first meeting, John will either continue missing meetings, or continue attending them.

(10) shows how (9) can be analyzed using local accommodation of a semantic presupposition (Heim1983). The idea is to fill in the presupposition in each of the conjuncts, so that in each conjunct the presupposition of continue is locally satisfied. With this representation the global context does not have to satisfy the presuppositions. In this analysis, this is the reason we intuit that the presuppositions in (9) do not project.

(10) John will either (have missed the first meeting and) continue missing meetings, or (have attended the first meeting and) continue attending them.

I would like to question this analysis by replacing the soft trigger continue with the hard trigger too in (11). The example is quite bad. In this scenario, if we pay attention only to the first two meetings, John will continue missing meetings and John will miss the second meeting too are equivalent in their assertions (that he does not attend the second meeting) and their presuppositions (that he did not attend the first meeting). In the same way, John will continue attending meetings is equivalent in its assertions and presuppositions to John will miss the second meeting too. 
(11) \# After the first meeting, John will either miss the second meeting too, or attend the second meeting too.

Let us repair (11) by local accommodation, exactly like we did in (10). (12) is the locally accommodated version of (11), and here the presupposition of too is locally satisfied in each conjunct.

(12) After the first meeting, John will either (have missed the first meeting and) miss the second meeting too, or (have attended the first meeting and) attend the second meeting too.

The problem now is that if both continue and too have semantic presuppositions, why is there such a difference in the possibility for local accommodation? Why should it be so much easier to locally accommodate the semantic presupposition of continue?

I assume that hard triggers do introduce a semantic presupposition. Since local accommodation is not possible with the hard trigger too in (11), we should not analyze the soft triggers continue with a semantic presupposition and use local accommodation to deal with (9).

In (13), I try to improve (11) by adding context which supplies more overt antecedents for the propositions presupposed by the two occurrences of too. The example (13a) is still bad.

(13) John will either attend the first meeting, or miss it.

a. \#? And he will either attend the second meeting too, or miss the second meeting too.

b. And he will either continue attending meetings, or continue missing them.

In addition to too, I regard also, even, again, negative polarity either, and the itcleft as hard triggers. 4 My hypothesis is that hard triggers encode semantic presuppositions in their semantic values, and that the pragmatic presuppositions triggered by soft triggers are easily suspendable and dependent on linguistic and extra-linguistic context because they do not come from semantic presuppositions. Soft triggers could be analyzed using semantic presupposition and local accommodation, but that isn't the right analysis, because we need to distinguish hard triggers from soft triggers. ${ }^{5}$

Stalnaker (1974) advocates this hypothesis, or suggests investigating it, except that he leaves it open whether there are semantic presupposition triggers. Chierchia and McConnell-Ginet (1990) and Simons (2001) advocate the hypothesis, and they think there are semantic presupposition triggers. ${ }^{6}$

In this program, one needs to find analysis of the triggering behavior of soft triggers which does not rely on semantic presuppositions. In the next two sections, I will review proposals for this made by Stalnaker and by Simons. 


\section{Stalnaker's analysis of know}

Stalnaker (1974) gives an outline of an analysis of know which I will partially paraphrase, and partially quote. We assume that both the factive implication of know and the belief implication are simple entailments. Consequently, know has two conceptually different entailments. Stalnaker basically says that it is confusing for a speaker to use know in a context where both of the entailments are at issue. Suppose a speaker used know and pragmatically presupposed neither the factive entailment nor the belief entailment. ("Suppose a speaker were to use $\mathrm{x}$ knows $P$ in a context where $P$ is in doubt or dispute.") Then he would be "saying in one breath something that could be challenged in two different ways. He would be leaving it unclear whether his main point was to make a claim that P" (i.e. to assert the factive implication), "or to make a claim about the epistemic situation of $x$ " (i.e. to assert the belief implication). If the speaker did that, he would be violating the presumption of being orderly, not confusing the listener, and not violating the reasonable expectations of the listener.

Both the speaker and hearer can be expected to recognize that it would violate maxims of conversation to use know in a context where both entailments are at issue. The hearer can be expected to infer that the speaker assumes the contrary, i.e. that one of the entailments is taken for granted. This gives a pragmatic presupposition that the factive entailment is true, leaving the belief entailment as the speaker's main point.

There are a couple of objections to Stalnaker's suggestion. First, the reasoning does not explain why the factive entailment rather than the belief entailment comes out pragmatically presupposed. For an utterance of (14), the above reasoning leads us to expect either a factive pragmatic presupposition that Mary and Bill are having an affair, or a belief pragmatic presupposition that John believes Mary and Bill are having an affair.

John knows that Mary and Bill are having an affair.

The choice between the two possibilities would presumably be made on the basis of plausibility in context. But clearly, only a factive presupposition is observed.

A second point is that Stalnaker's reasoning should apply to any verb with two conceptually distinct entailments. In (15), sell has two distinct entailments. The transfer entailment is that ownership of the bike went from John to Bill. The counter-transfer entailment is that ownership of some money went from Bill to John. By Stalnaker's logic, it would be confusing for the two entailments to both be pragmatically asserted. So, one of them should come out pragmatically presupposed. We either have a transfer presupposition (Bill got the bike) or a counter-transfer presupposion (John got the money). But our intuitions are that the two entailments are asserted, and neither of them is presupposed. This is supported by (16), where the sentence is conditionalized, and neither implication survives.

John sold his bike to Bill. 
(16) If John sold his bike to Bill, you can't use it now.

\# Transfer presupposition: Ownership of the bike went from John to Bill.

\# Counter-transfer presupposition: Ownership of some money went from Bill to John.

Finally, there are pairs with reversed assertions and presuppositions. (17) and (18) both have a factive implication (Mary and Bill are having an affair) and a belief implication (John believes they are). For know, we want the factive implication to come out presupposed, and for be right, we want the belief implication to come out presupposed. It is difficult to see how one can make (17) and (18) come out differently, if both have representations like (19) without a semantic presupposition.

(17) John is right that Mary and Bill are having an affair.

(18) John knows that Mary and Bill are having an affair.

(19) $\mathrm{p} \wedge \mathrm{x}$ believe $\mathrm{p}$

(20) a. semantically presuppositional know: $\partial \mathrm{p} \wedge \mathrm{x}$ believe $\mathrm{p}$

b. semantically presuppositional be right: $\partial[\mathrm{x}$ believe $\mathrm{p}] \wedge \mathrm{p}$

The consequence of this argument is that know and be right have to be distinguished somehow in their lexical meanings, in order for their pragmatic presuppositions to come out differently. This can easily be done with semantic presuppositions, as in (20). But conceivably, the difference is the additional implication of know which has to do with justification for belief, and which is not present with be right. In section 5, I will instead suggest that the distinction between know and be right is that they have different alternatives: the alternative to be right is be wrong, and the alternative to know is be unaware. ${ }^{7}$

\section{Simons' analysis}

Simons (2001) gives a derivation of the pragmatic presupposition of soft triggers using two generalizations or principles, which are stated and illustrated below.

Interpretation principle (IP)

If $\mathrm{x}$ raises the question whether $q$, and $q$ asymmetrically entails $p$, then $\mathrm{x}$ believes $p$.

$q=$ John knows Mary is having an affair

$p=$ Mary is having an affair

A: Does John know Mary is having an affair?

$q$ asymmetrically entails $p$

$\therefore$ A believes Mary is having an affair. 


\section{Question raising principle $(\mathrm{QR})$}

If A says $\mathrm{S}$, and $\mathrm{S}$ embeds $q$, then $\mathrm{A}$ raises the question whether $q$.

A: If John knows Mary is having an affair, then he will avoid the dinner.

"If John knows Mary is having an affair, then he will avoid the dinner" embeds "John knows Mary is having an affair."

$\therefore$ A raises the question whether Mary is having an affair.

In the examples we are interested in, inferences which are licensed by IP and QR chain together as follows.

(21) A: If John knows Mary is having an affair, then he will avoid the dinner.

A raises the question whether Mary is having an affair. (QR)

A believes Mary is having an affair. (IP)

Simons points out a problem of overgeneration in the analysis. Like Stalnaker's derivation, IP does not tell us which entailment of know comes out presupposed. Since John knows Mary is having an affair also asymmetrically entails that John believes Mary is having an affair, we can also derive a presupposition that John believes Mary is having an affair.

What about the validity of the principles? I am skeptical that the interpretation principle has any general validity. Consider a version of the sell argument from section 3. In (22), A explicitly raises the question whether John sold his bike to Bill. John sold his bike to Bill has, as asymmetric entailments, that ownership of the bike went from John to Bill, and that ownership of some money went from Bill to John. But in this case it is not necessary or even typical that the speaker A either believes that ownership of the bike went from John to Bill, or that ownership of some money went from Bill to John. ${ }^{8}$

A: Did John sell his bike to Bill?

I also think that between $\mathrm{QR}$ and IP there is a shift in the notion of raising a question. If $\mathrm{A}$ says $\mathrm{S}$ and $\mathrm{S}$ embeds $\mathrm{q}$, then $\mathrm{A}$ creates the potential for the question whether $\mathrm{q}$ becoming a topic of discussion. A does not explicitly raise the question, and in some cases he would want to avoid it. I think that if the interpretation principle is plausible at all, it has to do with cases where A explicitly raises a question, or where a question is a topic of discussion. If this point is right, the proof (21) is not valid, because there is a shift in the notion of raising a question.

\section{Lexical Alternatives}

I want to take advantage of the fact that the verbs we are talking about have intuitively obvious alternatives. The alternative to stop is continue, the alternative to win is lose, and so forth: 
(23)

\begin{tabular}{|l|l|c|}
\hline verb & alternative & C \\
\hline stop & continue & $\{$ stop, continue $\}$ \\
\hline win & lose & $\{$ win, lose $\}$ \\
\hline be right & be wrong & $\{$ be right, be wrong $\}$ \\
\hline know & be unaware & $\{$ know, be unaware $\}$ \\
\hline
\end{tabular}

In the right hand column of the table, I group the verb and its alternative into an alternative set $C$, using the notation of alternative semantics of focus (Rooth 1992). My hypothesis is that soft triggers contribute an alternative set to a discourse representation, but not the semantic presupposition that some alternative is true. Optionally, a speaker can pragmatically presuppose that some alternative in $C$ is true.

Consider example (24) which I assume refers to a contextual reference time $r$. The assertion is that John stopped smoking at $r$. The corresponding alternative is that John continued smoking at $r$.

John stopped smoking.

$C=\{$ John stopped smoking (at $r$ ), John continued smoking (at r) $\}$

Some proposition in $C$ is true:

John stopped smoking at $r \vee$ John continued smoking at $r$

$\equiv$ John smoked right before $r$

Both alternatives are simple propositions, and encode no semantic presuppositions. Each alternative entails that John smoked right before the reference time $r$. In general, to pragmatically presuppose that some alternative is true is to pragmatically presuppose the disjunction of the alternatives. The disjunction is in this case equivalent to John smoked right before $r$. So, if the speaker pragmatically presupposes that some alternative is true, he pragmatically presupposes that John smoked right before $r$, which is the observed presupposition for (24).

(25) shows how the derivation works for know and be right. Both have the same denotation, without a semantic presupposition, but they have different alternatives: the alternative for $x$ know $p$ is $p \wedge \neg$ believe $p$, while the alternative for $x$ be right that $p$ is $\neg p \wedge x$ believe $p$. When we take the disjunction of the alternatives, we get $p$ for know, and $x$ believe $p$ for be right. These are the pragmatic presuppositions we want.

\begin{tabular}{|c|c|c|c|}
\hline & denotation & alternative & disjunction \\
\hline $\mathrm{x}$ know $\mathrm{p}$ & $\mathrm{p} \wedge \mathrm{x}$ believe $\mathrm{p}$ & $\mathrm{p} \wedge \neg \mathrm{x}$ believe $\mathrm{p}$ & $\mathrm{p}$ \\
\hline $\mathrm{x}$ be right that $\mathrm{p}$ & $\mathrm{p} \wedge \mathrm{x}$ believe $\mathrm{p}$ & $\neg \mathrm{p} \wedge \mathrm{x}$ believe $\mathrm{p}$ & $\mathrm{x}$ believe $\mathrm{p}$ \\
\hline
\end{tabular}

Semantic approaches to presupposition have been criticized for stipulating results in lexical entries. Although I am suggesting a more pragmatic approach, it has the same degree of stipulation as semantic ones. To get different results for know and be right, I have to assume that the different alternatives are lexically 
encoded, or are derived in some other way from different lexical representations. I don't find this very problematic, particularly since alternative sets are used elsewhere in semantics, namely in the semantic of questions and focus.

\section{It-clefts and intonational focus}

The analysis I suggested connects with Rooth's (1999) comparison of it-clefts and intonational focus. In his football pool scenario, a betting contest called a football pool is held in the department, where people bet on the outcome of football games. Consider the exchange below.

A: Did anyone win the football pool this week?

B: Probably not, because it's unlikely that Mary $F$ won it, and she's the only person who ever wins.

Rooth's observation is that focus on Mary does not give an existential presupposition 'someone won the football pool' which projects to the top level. This is clear because A's question indicates that A does not know whether someone won, and so it is not common ground that someone won. In (27), we change the example by substituting an it-cleft for intonational focus. The result is quite bad, and this can be attributed to the it-cleft producing a semantic presupposition that projects to the top level. This presupposition is in conflict with the first thing that B says, namely probably not, meaning that probably nobody won the football pool.

A: Did anyone win the football pool this week?

B: \#Probably not, because it's unlikely that it's Mary $\mathrm{F}_{\mathrm{F}}$ who won it, and she's the only person who ever wins.

(28) is a representation for (26) which includes focus interpretation. $C$ is the set of propositions of the form ' $x$ won the football pool', and this set is introduced by focus interpretation. Because focus does not express an existential presupposition, there is no semantic presupposition that someone won the football pool. Notice by the way that the scope of the focus is the embedded sentence, but focus is justified non-locally, by A's question.

[probably not, because it's unlikely that [[Mary ${ }_{F}$ won it $\left.\left.] \sim C\right]\right]$

Rooth uses these data as an argument against analyses where intonational focus introduces a semantic existential presupposition. Instead, he says, focus just introduces an alternative set. Extending this point, we can say that focus introduces an alternative set, which is turned into a pragmatic existential presupposition if the speaker pragmatically presupposes that some alternative is true. This explains why one often has feeling that intonational focus gives rise to an existential presupposition. Exactly like with the soft triggers, this presupposition is optional and can occurs only when it fits into the context. So, 
we can regard focus as another soft trigger, which sometimes gives a pragmatic presupposition and sometimes not, depending on context.

\section{Pragmatics of the derivation}

I want to say that when an alternative set is around in the discourse representation, a speaker can optionally make the pragmatic presupposition that some alternative is true. This sounds plausible enough, but more has to be said about it, because it does not fall out of the logic of communication that random pieces of information can be presupposed at the whim of the speaker. Why isn't the presupposition something different, such as some alternative being false, or every alternative being unpleasant?

The answer has to do with the typical role of alternative sets in discourses and conversations. Typically, when a set of alternative propositions are discussion (or as I will say, when the alternative set is topical), it is taken for granted that some alternative is true, and the conversants are trying to establish which one it is, or to narrow down the possibilities. One case of this is alternative sets which are introduced as the semantic values of questions. On Hamblin's (1973) semantics for questions, the question who ate the last piece of cake introduces the set of propositions

$$
\text { \{ } x \text { at the last piece of cake } \mid x \text { is a person }\}
$$

as the semantic value of the question. In most cases where this question is used, it would be taken for granted that some alternative is true.

This typical role for alternative sets in discourse makes it possible for a speaker to pragmatically presuppose that some alternative is true, because in a context where the presupposition is plausible, the speaker can expect the hearer to recognize his intention to make the assumption. The speaker can presuppose that some alternative is true, because this is indeed the typical case when an alternative set is topical in a discourse.

(29)-(32) show how it works out in some examples involving know. As an expository notation, I write a description of the alternative set $C$ into the logical form, next to the sentence which is headed by know. This corresponds to the hypothesis that the lexical entry for know includes a representation of a set of alternatives, each of which is obtained by combining a contrasting function (either unaware or know) with the same arguments as are used for know in building the propositional denotation (in this case, the complement denotation rain, and the subject denotation $j$ ).

(29) assertion: John knows it is raining.

alternative: John is unaware it is raining

$C=\{$ John knows it is raining, John is unaware it is raining $\}$

$=\{$ rain $\wedge j$ believe rain, rain $\wedge \neg$ j believe rain $\}$

disjunction of alternatives: rain

John knows it is raining.

[[John knows it is raining]

$$
\mathrm{C}=\{\text { rain } \wedge j \text { believe rain, rain } \wedge \neg j \text { believe rain }\}]
$$


(31) John doesn't know it is raining.

[not [[John knows it is raining]

$$
\mathrm{C}=\{\text { rain } \wedge j \text { believe rain, rain } \wedge \neg j \text { believe rain }\}]\}
$$

(32) If John knows it is raining, he won't go outside.

[If [[John knows it is raining]

$$
\mathrm{C}=\{\text { rain } \wedge j \text { believe rain, rain } \wedge \neg j \text { believe rain }\}]
$$

[not [he will go outside]]]

The effect of these representations is that the alternative set $C$ is made available at the discourse level. In each example, $C$ consists of the two propositions rain $\wedge j$ believe rain and rain $\wedge \neg j$ believe rain. Now we run the pragmatic story: at the discourse level, the alternative set $C$ is interpreted as a topical alternative set. Typically, some alternative in a topical alternative set is assumed to be true, and both the speaker and hearer are aware of this. Therefore the speaker (when this is plausible in context) can pragmatically presuppose that it is raining.

Summarizing, soft triggers contribute an alternative set to the discourse representation. Such alternative sets are typically construed as topical in a discourse, and where an alternative set is topical, it is typically the case that some alternative is assumed to be true. The pragmatic presupposition of soft triggers results from a default inference to this typical scenario. ${ }^{9}$

\section{Compositional interactions}

There is a group of observations about the presupposition projection which are considered characteristic of semantic presupposition, because simple and explanatory accounts of them have been given in compositional semantic accounts using semantic presupposition (Karttunen 1974, Heim 1983). One case is the transformation of presuppositions in conditionals. In isolation, (33) presupposes that John has twins; this presupposition $q^{\prime}$ comes from the definite description. ${ }^{10}$ In a conditional context (34), the presupposition $q^{\prime}$ is weakened to $p \rightarrow q$, where $p$ is the assertion of the if-clause (in this case, that John has children).

(33) Mary does not like John's twins.

$>$ John has twins. (presupposition $q^{\prime}$ )

(34) If John has children, Mary does not like his twins.

$>$ If John has children then he has twins. (presupposition $p \rightarrow q$ )

This transformation of presuppositions is explained in a dynamic compositional account using semantic presuppositions (Heim 1983). The potential problem for my analysis is that when we check similar examples with soft triggers, the data come out in the same way, with conditional weakening of the presupposition. Here is an example with stop.

John has stopped smoking Luckies. 
$>$ At some past time, John smoked Luckies.

If John ever smoked, then he has stopped smoking Luckies.

$>$ If John ever smoked, then at one time he smoked Luckies

It seems clear to me that the presupposition that John used to smoke Luckies is conditionally weakened in the way shown in (36). If conditional weakening is characteristic of semantic presupposition, this looks like evidence for a semantic treatment of the presupposition of stop.

Another compositional interaction is trapping by bound variables in quantified contexts. This is discussed in van der Sandt (1992); see also the discussion of the argument in Beaver (1997). In (37), the subject of stop is a quantified noun phrase everyone in the house. As a consequence, the alternatives generated by stop have a bound variable in them, as shown in the description of $\mathrm{C}$ in the last part of the labeled bracketing. ${ }^{11}$

(37) Everyone in the house stopped smoking.

[everyone in the house] $]_{2}$

[e $e_{2}$ stopped smoking $\mathrm{C}=\left\{\mathrm{x}_{2}\right.$ smoke before $\mathrm{r}$ and $\mathrm{x}_{2}$ stop smoking at $\mathrm{r}$, $x_{2}$ smoke before $r$ and $x_{2}$ smokes at $\left.\left.r\right\}\right]$

The problem for my analysis is that there is no single value for $C$ at the utterance level. This makes it unclear how my pragmatic derivation from section 7 should deal with the example, since it talks about alternative sets which are topical at the discourse level.

These two problems (presupposition projection and trapping by bound variables) are similar, because they involve interactions with compositional semantics. Accounts which assume lexical semantic presuppositions have the resources to deal with them, because they manipulate semantic objects which encode presuppositions. Furthermore, since the problems have to do with what is happening at embedded levels in the sentence, they seem to involve compositional semantics, rather than pragmatics. And finally, these phenomena have been analyzed in the literature on semantic presupposition, and some of the analyses of presupposition projection are compellingly simple. How could a pragmatic account do as well?

I will deal with this puzzle by formulating the pragmatic account in dynamic semantic terms, taking advantage of the same dynamic compositional interactions which are used in semantic accounts of presupposition projection.

I take it as axiomatic that the basic communicative act which is involved in pragmatic presupposition relates to a global common ground. To make a pragmatic presupposition is to communicate that one believes the common ground for a discourse to have such-and-such entailments. Thus making a pragmatic presupposition is, by definition, a global communicative act. On the other hand, in the case of the compositional phenomena above, it seems that one has to consider what information is available in a local compositional context: this is what semantic theories do when they check semantic presuppositions against a local information state. This creates a tension between the global and local information levels. 
To resolve the tension, I will use a strategy one could call think locally, act globally. The strategy is also used in David Beaver's work on accommodation (Beaver 1994). Whether some alternative is true will be checked against a local context, instead of a global context. But pragmatic presupposition will still be global.

In the examples below, $c$ is the global context (information state or file) for the sentence which embeds know, and $d$ is the corresponding local context for know. The local context $d$ is determined by $c$ and by compositional semantic rules. The point of the examples is to argue that in typical uses in a global context $c$ of a sentence $\mathrm{S}$ embedding know, the corresponding local context $\mathrm{d}$ for know entails that some proposition in the alternative set determined by know is true. This will be abbreviated $d$ ksome $(C)$.

The first example (38) is a negation. In this compositional environment, know introduces the alternative set $C$ given at the end in the labeled bracketing. The fourth line gives the compositional semantic rule for negation from Heim (1983). When the rule is applied to this case, $\varphi$ is the clause headed by know. The local context for know is read off the file change rule: it is the context variable on the left in the subexpression $(c+\varphi)$. In other words, the local context for know in this case is the global context $c$. This is stated on the bottom line in the example.

John doesn't know it is raining. [not [ John know it is raining

$$
C=\{\text { rain } \wedge \text { believe(j,rain), rain } \wedge \neg \text { believe(j,rain })\}]]
$$

File change rule: $c+\neg \varphi=c-(c+\varphi)$

$$
d=c
$$

I assume that, typically, the alternative set $C$ in such examples is construed as topical at the discourse level, and that furthermore, when an alternative set is topical, it is typically presupposed that some alternative is true. Putting these together, in a typical use of such negated examples, we have $c$ some $(C)$, where $c$ is the global context. Since the local context $d$ for know equals the global context $c, d$ some $(C)$.

Notice that in this reasoning, it is important that $C$ is (or can be) interpreted as topical, even though it is introduced in an embedded position. This connects with what I said about the focus example (26), where an alternative set introduced at an embedded level is justified at the discourse level, in that case by the question.

In the next example, know is embedded in the if-clause of a conditional. The reasoning is as in the previous example. In the file change rule for the conditional from Heim (which actually is a dynamic rule for a material implication), the local context $d$ for $\varphi$ is the global context $c$. Reasoning as before, in typical uses of sentences with this kind of embedding for know, $d$ ksome $(C)$. 
If John knows it is raining, he won't arrange to go out for lunch.

[if [John knows it is raining

$$
C=\{\text { rain } \wedge \text { believe(j,rain), rain } \wedge \neg \text { believe(j,rain) }\}]
$$

[he won't arrange to go out for lunch]]

File change rule: $c+$ if $\varphi$ then $\psi=c-(c+\varphi-c+\varphi+\psi)$ $d=c$

In (40), know is in the main clause of the conditional, instead of the ifclause. I think that intuitively, the alternative set $C$ has the same status as in the previous examples: the example fits into a discourse where $C$ is topical, and typically it would be assumed that some alternative is true.

If John has been outside, he knows it is raining.

[If John has been outside

[he knows it is raining

$$
C=\{\text { rain } \wedge \text { believe(j,rain), rain } \wedge \neg \text { believe(j,rain })\}]]
$$

In this case, I do not want to say that it is necessarily typical of uses of sentences with this general pattern of embedding that some alternative in $C$ is true. The reason is that in examples like (41), it is debatable whether $C$ is topical at the discourse level, and it is clear that at the discourse level, it is not presupposed that some alternative is true. That is, it is not presupposed that it is raining.

(41) If it is raining, then John knows it is raining.

So, I will say something weaker: when know is embedded in the main clause of a conditional, then frequently the associated alternative set $\mathrm{C}$ is topical in the discourse, and it is assumed that some alternative is true. In such cases, we can reason as follows. The file change rule for the conditional is

$$
c+\text { if } \varphi \text { then } \psi=c-(c+\varphi-c+\varphi+\psi)
$$

and therefore the local contex for $\psi$ is $\mathrm{c}+\varphi$, i.e. $c+J o h n$ has been outside. In a context where $C$ is topical and where the global information state $c$ entails that some alternative is true, we also have that $c+$ John has been outsideksome $(C)$. That is, $d$ ksome $(C)$.

Taken together, these examples support the following generalization.

In typical uses in a global context $c$ of a sentence $\mathrm{S}$ which embeds $x$ know $p$, the corresponding local context $d$ for $x$ know $p$ entails $p$.

The justification for this is that, when $\mathrm{C}$ is $\{p \wedge$ believe $(x, p), p \wedge \neg$ believe $(x, p)\}$, $d \vDash$ some $(C)$ is equivalent to $d \vDash p$.

As I have justified it, the generalization follows from the alternatives suggested by know, not from a semantic presupposition of know. I am assuming that know has no semantic presupposition. 
Now I want to derive the pragmatic presupposition. Basically, I want to argue that the situation of the local context $d$ entailing $p$ is so typical that it carries over to other cases. Suppose that a speaker A uses any of the sentences $\mathrm{S}$ above which embed $x$ know $p$. The hearer B is unsure whether the global context $c$ is such that the corresponding local context $d$ for $x$ know $p$ entails $p$. But B takes A's utterance as an indication that $\mathrm{A}$ thinks the global context is like that. B silently accommodates the assumption.

A speaker can expect a listener to reason in this way. That is, a speaker can expect a listener to assume that, in the absence of evidence to the contrary, the global context $c$ is such that the corresponding local context for $x$ know $p$ entails $p$. This gives a default pragmatic presupposition that the global context for $\mathrm{S}$ is such that the corresponding local context for $x$ know $p$ entails $p .^{12}$

\section{Dynamic compositional filtering of pragmatically triggered presuppositions}

Here is the conditional weakening example which was discussed earlier, where we see the projection behavior which we used to think was characteristic of semantic presupposition.

(43) If John ever smoked, then he has stopped smoking Luckies.

$>$ If John ever smoked, then at one time he smoked Luckies.

By the method of the previous section, we derive the following condition on a common ground $c$.

$c$ is such that the corresponding local context $d$ for he has stopped smoking Luckies entails that John once smoked Luckies.

Using the compositional derivation for (43), we find that the corresponding local context $d$ is $c+$ John once smoked. So, the condition is equivalent to

$c+$ John once smoked entails that John once smoked Luckies.

This corresponds to the presupposition which is perceived intuitively. An example of a context which supports this is one where it is taken for granted that John is one of a group of friends who, if they ever smoked, started smoking as teenagers, and started with Luckies. It is also the same presupposition which is derived on an account which says that stop encodes a semantic presupposition in its lexical meaning. In my analysis, hard triggers like clefts do introduce semantic presuppositions, and for them presupposition projection looks the same as for soft triggers. So, the analysis derives the same projection behavior for hard and soft triggers. The reason this happens is that both the semantic and pragmatic derivations check something (either the truth of a semantic presupposition, or some alternative being true) against a local context $d$ which obtained (in exactly 
the same way in the two cases) from a global context $c$ and dynamic compositional semantics.

There is discussion in the literature which says that this result is desirable. Chierchia and McConnell Ginet (1990) say that semantically and pragmatically triggered presuppositions should be filtered or transformed in the same way by dynamic compositional semantics:

While there can be two sources of presuppositions, we would expect that their projection properties are the same since the context-change potential of nonatomic sentences is independent of how the presuppositions of atomic sentences are triggered. (Chierchia and McConnell-Ginet 1990, p. 313)

This position is also taken by Kadmon (2001). I find it superficially a puzzling one, because pragmatic reasoning is reasoning about utterances, and pragmatic derivations of implications (for instance, the pragmatic derivation of quantity implicatures) reasons about utterance denotations. How could dynamic compositional semantics, which assembles denotations of parts of an utterance into an utterance denotation, have the chance to filter a presupposition which is derived from conversational reasoning about an utterance denotation?

It would be a mistake to think that this point is automatically countered by the fact that current theories use dynamic semantic objects for both compositional semantics and pragmatics, or that the information states which are used in dynamic compositional semantics are sometimes called "hypothetical contexts." The $d$ 's of the previous section are information states used in compositional semantics; they are not utterance contexts. Therefore pragmatic arguments do not automatically apply to them in the same way as they apply to utterance contexts.

My solution escapes the problem, because it does not strictly separate pragmatics from compositional semantics. The pragmatic generalization (42) refers to an embedded information state $d$. If we just have the semantic value of the sentence (a certain dynamic proposition or file change potential), it is not possible to apply the condition, because to apply it, one has to find the $d$ which corresponds to the global $c$. To apply the condition, one has to have access to something like a structured proposition (Lewis 1972) which stores the pieces from which the semantic value is composed. Given a structured dynamic propostion, one can find the local context for the soft trigger, given the global context. This is a less strict separation of semantics from pragmatics, because more of the semantics is visible to the pragmatics. I emphasize, though, that the pragmatic derivation of the presupposition of soft triggers maintains Stalnaker's definition of a pragmatic presupposition as a communicated assumption about the common ground. In the pragmatics I am suggesting, we are allowed to think locally, but we still act globally. 


\section{Endnotes}

* I would like to thank David Beaver, Cleo Condoravdi, Pauline Jacobson and Sally McConnell-Ginet for useful comments and references. Special thanks to Mats Rooth for insightful conversations over issues discussed in this paper.

${ }^{1}$ Both versions are a naive lexical semantics for know, since they do not entail anything about the source of $x$ 's belief that $p$. I hope this does not affect the arguments I will make, but it might.

2 The default account of semantic presuppositions which I have in mind is Heim's file change theory, Heim (1983). In the beginning part of the paper this is not important, but in section 8 , I will make crucial use of a dynamic compositional semantics.

${ }^{3}$ Stalnaker's paper also presents the general framework for presupposition which I will assume here.

${ }^{4}$ Negative polarity either is exemplified in John didn't attend either. There are examples of suspension with it-clefts, but I assume these have a different character, involving discourse subordination. See Chierchia and McConnellGinet (1990) for discussion. Here is an example.

A. Was it you who let the cat out the back door?

B. No, it wasn't me who did it, because I haven't been in the kitchen. And it wasn't Sally who did it, because she just arrived. In fact I suspect nobody did it. The cat sometimes gets out through the window.

${ }^{5}$ Or if both hard and soft triggers have semantics presuppositions, one has to find another explanation for the difference in suspendability. A couple of ideas occur to me. Almost all of my hard triggers are adverbs which express no meaning apart from the presupposition. To use one of these presuppositional adverbs, while intending a representation where the presupposition is locally accommodated and thereby turning the presupposition into an assertion, is a very indirect and complicated way of introducing asserted information. Because they are so indirect and complicated, such representations are not used.

Another point is that hard triggers all associate with focus. Maybe the fact that the focus itself requires a contrasting antecedent makes it harder to suspend the presupposition.

${ }^{6}$ Kadmon (2001) takes a different position: she argues, first, that it is hard to draw a clean line between hard and soft triggers, and second, that it does not matter much for theoretical issues like presupposition filtering and accommodation whether presuppositions are semantically or pragmatically triggered.

7 Fillmore points out similar pairs, such as accuse and criticize, which have assertions and presuppositions permuted in various ways. I think none of his examples are completely symmetric. 
${ }^{8}$ Notice that the facts are different if sell has a contrastive stress. In this case, A can be understood as conveying (and in fact, presupposing) that ownership of the bike went from John to Bill. I discuss such data in section 6.

${ }^{9}$ This can be correlated in a number of ways with Simons' analysis. First, note that a set of alternative propositions is a question. Simons' question raising principle is comparable to my appeal to lexically specified alternatives: according to both of them, an embedded soft trigger can introduce a question. However, the questions are different. For Simons, the question introduced by $x$ knows $p$ is

$$
\{p \wedge \operatorname{believe}(x, p), \neg[p \wedge \operatorname{believe}(x, p)]\},
$$

because this is the question whether $x$ knows $p$. For me, the question introduced by $x$ knows $p$ is

$$
\{p \wedge \text { believe }(x, p), p \wedge \neg \text { believe }(x, p)\},
$$

with a narrower scope for the negation. Another difference is that, where she says that the question is raised, I would say that the question is presupposed to be topical in the discourse.

Simons' interpretation principle is generally comparable to my reasoning about topical questions. This is brought out in the following formulations.

If $x$ raises the question whether $q$, and $q$ asymmetrically entails $p$, then $\mathrm{x}$ believes $\mathrm{p}$.

If a question $\mathrm{C}$ is topical, then typically, the common ground $\mathrm{c}$ entails some element of $\mathrm{C}$.

Here the most important difference is that Simons refers to the speaker's beliefs, and I refer to the common ground.

${ }^{10}$ Actually, it is not clear that the definite description is a hard trigger, since it's presupposition is suspendable.

${ }^{11}$ There is work to do in making this representation semantically sensible, since the values for $C$ have to be allowed to vary with the choices of $x_{2}$. I expect that this can be resolved by quantifying $C$ inside the scope of everyone, perhaps with an existential quantifier.

${ }^{12}$ Notice that, although I used lexical alternatives to obtain (42), at this point in the argument, the important thing is that in typical uses, the global context $c$ is such that the corresponding local context for the soft trigger entails the presupposition of the soft trigger. The argument would work just as well if there were another reason for this, which did not have to do with alternatives. For aspectual verbs like stop, and in fact for all soft triggers which entail a change of state, I think there is another possibility, which uses the fact that we are better informed about the past than the future. One could try to argue that, in typical uses of John stopped smoking (at r), it is common ground whether John smoked before $\mathrm{r}$ or not, simply because conversants are typically well-informed about facts up to a certain point in time. 


\section{References}

Beaver, D. (1994) "Accomodating Topic". In Sandt van der, R. and Bosch, P. (eds.) The Proceeding of the IBM/Journal of Semantics Conference on Focus, vol 3, IBM Heildelberg.

Beaver, D. (1995) Presuppositions and Assertions in Dynamic Semantics, Ph.D dissertation, University of Edinburgh.

Beaver, D. (1997) "Presupposoition". In Benthem J. van, and Meulen A. ter (eds,) The Handbook of Logic and Language. Elsevier.

Fillmore, C. (1971) "Verbs of Judging: An Exercise in Semantic Description". In Fillmore, C. and Langendoen, T. (eds.) Studies in Linguistic Semantics. Holt, Reinhart and Winston, Inc.

Hamblin, C. (1973) "Questions in Montague English". Foundations of Language 10.

Heim, I. (1983) "On the Projection Problem of Presuppositions", in Barlow, M., Flickinger, D. P. and Westcoat, M. T. (eds.) Proceedings of WCCFL II, CSLI, Stanford University.

Kadmon, N. (2001) Formal Pragmatics. Blackwell Publishers.

Kartuneen, L. (1971) "Some Observations on Factivity." Papers in Linguistics 5.

Kartuneen, L. (1974) "Presuppositions and Linguistic Context". Theoretical Linguistics 1.

Lewis, D. (1972) 'General Semantics”, in Davidson, D. and Harman, G. (eds.) Semantics for Natural Language. Dordrecht:D.Reidel.

Rooth, M (1992) “A Theory of Focus Interpretation”. Natural Language Semantics 1.

Rooth, M. (1999) “Association with Focus or Association with Presupposition?" In Bosch, P. and Sandt R. van der (eds.), Focus- Linguistic, Cognitive, and Computational Perspectives. Cambridge University Press.

Sandt, R. van der (1992) "Presupposition Projection as Anaphora Resolution". Journal of Semantics 9.

Simons, M. (2001) "On the Conversational Basis of some Presuppositions." In Hasting, R., Jackson,B. and Zvolenzky, S. (eds.) Proceedings of SALT 11, CLC publications, Cornell University.

Stalnaker, R, (1974) "Pragmatic Presuppositions." In Munitz, M. and Unger, P. (eds.) Semantics and Philosophy. New York: New York University Press. 